\title{
Multidimensional structure of acute mania: influence of affective
} temperaments

\author{
Hagop Akiskal*1, Elie-Georges Hantouche ${ }^{2}$, Jean-Michel Azorin ${ }^{3}$, \\ Sylvie Lancrenon ${ }^{4}$, Liliane Chatenet-Duchene ${ }^{5}$ and Charles Gury ${ }^{5}$
}

Address: ${ }^{1}$ International Mood Center, UCSD, San Diego, USA, ${ }^{2}$ Mood Center, Université Paris Vi, Pitié-Salpetriere Hospital, Paris, France, ${ }^{3}$ Sainte Marguerite Hospital, Marseille, France, ${ }^{4}$ Sylia-Stat, Antony, France and ${ }^{5} \mathrm{CNS}$ Department Sanofi-Aventis, Paris, France

* Corresponding author

from International Society on Brain and Behaviour: 2nd International Congress on Brain and Behaviour

Thessaloniki, Greece. 17-20 November 2005

Published: 28 February 2006

Annals of General Psychiatry 2006, 5(SuppI I):SI 40 doi:I0.I I86/I744-859X-5-SI-SI 40

\section{Background}

Previous data deriving from EPIMAN (104 patients) study had suggested a rich multidimensional phenomenology of mania beyond the conventional dichotomy of euphoric versus dysphoric forms (Akiskal et al., 2003).

\section{Materials and methods}

"EPIMAN-II Thousand" is a national multi-site collaborative study dedicated to the clinical sub-types of mania. It involved training 317 French psychiatrists working in different sites representative of all France. The study actually succeeded in recruiting 1090 cases admitted for acute mania (DSM-IV criteria). Manic symptomatology was assessed using the Mania Rating Scale (MRS; 10 items). A checklist of depressive symptoms, CLDS (McElroy et al. modified, 10 items) and MADRS (10 items) were used to assess co-existing depression. Principal component analysis (PCA) was conducted after rotation on combined items from MRS + MADRS (20 items). Affective Temperaments (AT) were assessed by using the full TEPMS-A French version (84 items, Hantouche et al., 2001). Correlation analyses were conducted between mean factorial scores and mean scores of the TEMPS-A.

\section{Results}

The PCA conducted on the combined "MRS + MADRS" showed, after varimax rotation the presence of 5 major components: core factor "Depression-SAD1" (eigenvalue = 3.7), "Mania-GLAD" ( ev = 3.0), "Sleep difficulties" ( ev = $1.8)$, "Psychomotor Inhibition-SAD2" ( $\mathrm{ev}=1.7)$, and "Poor Judgment-Irritability-BAD" (ev = 1.6). Correlation coefficients were statistically significant between: factor GLAD and Hyperthymic Temperament, factor SAD- and
Depressive Temperament, factors SAD1/SAD2 and Cyclothymic Temperament, and finally between factor BAD/SAD1 and Irritable Temperament. Rates of cases with Cyclothymic, Depressive, and Irritable Temperaments were significantly $(\mathrm{p}=0.0022)$ higher in Mixed Mania versus Pure Mania (respectively $75 \%$ vs $44 \%$, 37\% vs $22 \%, 30 \%$ vs $21 \%$ ).

\section{Discussion}

Our data obtained on the largest population of manic patients ever conducted $(n=1090)$ confirmed the multidimensionality of manic syndrome and the major pathoplastic role of Affective Temperaments in modulating the clinical expression of mania.

\section{Funding source}

unrestricted grant from Sanofi-Aventis.

\section{References}

I. Akiskal HS, et al.: Proposed multidimensional structure of mania; beyond the euphoric-dysphoric dichotomy. J Affect Disord 2003, 73:7-18.

2. Hantouche E, Kochman F, Akiskal HS: Evaluation des temperaments affectifs: version complete des outils d'auto-evaluation. Encephale 200I, 27:24-30. 